\title{
Relationship between residual syntax score and in hospital outcomes in patients undergoing primary percutaneous intervention
}

\author{
Primer perkütan koroner girişim yapılan hastalarda rezidüel syntax skoru \\ ile hastane içi sonlanımların ilişkisi
}

\author{
Altuğ ÖSKEN ${ }^{1}$, Mehmet Bülent VATAN ${ }^{2}$, Ercan AYDIN ${ }^{2}$, Salih ŞAHINKUŞ ${ }^{2}$, Selçuk YAYLACl ${ }^{3}$, Yusuf CAN ${ }^{2}$, \\ İbrahim KOCAYiĞiT², Hüseyin GÜNDÜZ², Ramazan AKDEMiR ${ }^{2}$
}

\begin{abstract}
In our study, we aimed to detect the relation between residual SYNTAX score which can be considered as a quantitative measurement of residual ischemia and inhospital outcomes the patients with diagnosis of ST-elevation myocardial infarction who will undergo percutaneous coronary intervention. One hundred and five patients meeting the eligibility criteria were included to the study. Complete revascularization was defined as $r S S=0$ and incomplete revascularization as $r S S \geq 1$. Clinical, demographic data, laboratory values, angiographic, procedural characteristics, characteristics of the lesion, different scoring systems and inhospital endpoints were compared between groups. Thirty-five patients $(33.3 \%)$ were in rSS $=0$ Group and 70 patients $(67.7 \%)$ in rSS $\geq 1$ Group. 86 patients (81.9\%) were male and 19 (18.1\%) were female. Among demographic data age, height, history of hypertension, cigarette smoking were statistically significant between groups $(p<0.05)$. Laboratory values did not differ statistically significantly between groups ( $p>0.05)$. Among angiographic characteristics stent length and diameter differed statistically significantlyf between groups $(p<0.05)$. There was no significant difference in lesion characteristics ( $p>0.05)$. Only recurrent ischemia from in-hospital outcomes was significantly higher in the $R S S \geq 1$ group which was defined as incomplete revascularization group ( $p<0.05)$. Residual SYNTAX score which was calculated as an indirect marker of incomplete revascularization does not adequately predict inhospital endpoints in patients with STEMI. In this regard randomized controlled and more extensive studies are needed to demonstrate long-and short-term mortality.
\end{abstract}

Key words: ST-elevation myocardial infarction, primary percutaneous coronary intervention, incomplete revascularization, SYNTAX score öz

Çalışmamızda, ST yükselmeli myokard enfarktüsü tanısıyla primer perkütan koroner girişim uygulanan hastalarda, inkomplet revaskülarizasyonun kantitatif bir ölçümü olarak kabul edilebilecek rezidüel SYNTAX skoru ile hastane içi dönemdeki sonlanım noktaları arasındaki ilişkiyi saptamak amaçlanmıştır. Çalışmaya, uygunluk kriterlerini karşılayan 105 hasta alındı, rSS=0 olan grup komplet revaskülarizasyon, $r S S \geq 1$ olan grup ise inkomplet revaskülarizasyon olarak tanımlandı. Hastaların klinik, demografik verileri, laboratuvar değerleri, anjiografik, prosedürel karakteristikleri, lezyon özellikleri, farklı skorlama sistemleri ve hastane içi sonlanım noktaları gruplar arasında karşılaştırıldı. Vakaların $35^{\prime}$ inde $(\% 33,3)$ rSS $=0,70$ 'inde $(\% 67,7)$ rSS $\geq 1$ bulundu. Vakaların 86'sı $(\% 81,9)$ erkek, 19'u $(\% 18,1)$ kadındı. Gruplar arasında demografik verilerden yaş, boy, hipertansiyon öyküsü, sigara içiciliği açısından istatistiksel anlamlı fark bulundu ( $p<0,05)$. Laboratuvar değerleri açısından anlamlı fark bulunmadı $(p>0,05)$. Anjiografik karakteristiklerden stent uzunluğu ve çapı açısından gruplar arasında anlamlı fark saptandı $(p<0,05)$. Lezyon özellikleri açısından anlamlı fark saptanmadı $(p>0,05)$. Hastane içi sonlanım noktalarından yalnızca rekürren iskemi $r S S \geq 1$ olan inkomplet revaskülarizasyon grubunda istatistiksel anlamlı yüksek saptan$d_{\imath}(p<0,05)$. Inkomplet revaskülarizasyonun dolaylı bir belirteci olarak hesapladığımız rezidüel Syntax skoru STEMI hastalarında hastane içi sonlanım noktalarını öngördürmekte yeterli olamamaktadır. Bu konuda uzun ve kısa dönem mortaliteyi göstermek açısından daha geniş kapsamlı randomize kontrollü çalışmalara ihtiyaç vardır.

Anahtar kelimeler: ST yükselmeli myokard enfarktüsü, primer perkütan koroner girişim, inkomplet revaskülarizasyon, SYNTAX skoru

Received: 24.01 .2016

Accepted: 23.02 .2016

${ }^{1}$ Siyami Ersek Thoracic and Cardiovascular Surgery Center, Training and Research Hospital, Department of Cardiology

${ }^{2}$ Sakarya University Faculty of Medicine, Department of Cardiology

${ }^{3}$ Rize Fındıklı Guatr Research Center, Department of Internal Medicine

Yazışma adresi: Altuğ Ösken, Siyami Ersek Thoracic and Cardiovascular Surgery Center, Training and Research Hospital, Department of Cardiology, İstanbul e-mail: alosk@hotmail.com 


\section{Giriş}

ST yükselmeli myokard enfarktüsü (STEMI), tanı ve tedavideki önemli gelişmelere rağmen, özellikle gelişmekte olan ülkelerde en önemli toplum sağlığı sorunu olmaya devam etmektedir. Ülkemizde 1990 yılından bu yana yürütülmekte olan TEKHARF (Türk Erişkinlerinde Kalp Hastalığı ve Risk Faktörleri Taraması) çalışmasının verilerine dayanarak ölüm nedenlenleri bakıldığında, koroner kalp hastalığı nedenli ölümlerin, tüm ölümlerin yaklaşık \%42'sini oluşturduğu ve yeni gelişen koroner olaylar ile nüfus artış hızı oranlandığında koroner kalp hastalarının sayısının yılda 200000 kişi civarında yükseldiği öngörülmektedir ${ }^{1,2}$.

STEMI tanısı konulan hastalarda, trombüs ile tam tıkanmış olan koroner arterde yeniden açıklık ve kanlanmanın sağlanması için en erken zaman diliminde koroner yoğun bakım koşullarında trombolitik ilaçlarla tedavi ve/veya kateter laboratuvarlarında perkütan koroner girişim (PKG) uygulanmaktadır. Primer PKG'nin gelişimi ve yaygın kabulüyle birlikte akut myokard enfarktüsü (AMI) yönetiminde büyük gelişmeler kaydedilmiştir ${ }^{3}$.

Koroner arter hastalığı (KAH) tanısıyla müdahale planlanan hastalarda komplet revaskülarizasyonun (KR) başarılması istenilen bir durumdur. PKG'deki büyük teknik gelişmelere rağmen, komplet revaskülarizasyonun elde edilmesi hâlen çok sık değildir. PKG sonrası inkomplet revaskülarizasyonun (IR) prognostik etkisi çalışmalar arasında tutarsızdı ${ }^{4-6}$. Evrensel olarak kabul edilmiş bir inkomplet revaskülarizasyon tanımlaması yoktur ve PKG sonrası rezidüel koroner darlıkların ciddiyeti, derecesi ve niteliğinin hasta sonlanımlarında farklı etkilere sahip olduğu söylenilebilir. SYNTAX (SYNergy between PCI with TAXUS and Cardiac Surgery) skorlama sistemi, revaskülarizasyon öncesi, kantitatif ve yinelenebilir temel bir ölçüm olması nedeniyle koroner anatomik ciddiyet ve karmaşıklığı gösterebilir, PKG yapılan hastalarda bağımsız prognostik değişken olarak kullanılabilir ${ }^{7-11}$.

Çalışmamızda, STEMI tanısıyla primer PKG uygulanan hastalarda, prosedür sonrası hesaplanan, inkomplet revaskülarizasyonun kantitatif bir ölçümü olarak kabul edilebilecek rezidüel SYNTAX skoru ile hastane içi dönemdeki sonlanım noktaları arasındaki ilişkiyi göstermeyi amaçladık.

\section{GEREÇ ve YÖNTEM}

Çalışmamız, 2011 Nisan-2012 Ekim ayları arasında akut ST segment yükselmeli myokard enfarktüsü tanısı konularak Sakarya Üniversitesi Eğitim ve Araştırma Hastanesi kateter laboratuvarında primer PKG uygulanan hastaların geriye dönük olarak dosya kayıtlarının taramasıyla gerçekleştirilmiştir. Çalışma, Sakarya Üniversitesi Tıp Fakültesi Girişimsel Olmayan Etik Kurulundan 26.11.2012 tarihinde "B.30.2.SAÜ.0. 20.05.05050.01.04/6" sayı numarası ile onay alınarak hazırlanmıştır.

\section{Çalışmaya alınma kriterleri}

1. Elektrokardiyografide $\geq 2$ komşu derivasyonda $\geq 1$ $\mathrm{mm}$ ST elevasyonu olan veya yeni başlangıçı sol dal bloğu bulunan STEMI hastaları

2. Göğüs ağrısının başlangıcından itibaren $<12$ saat süre geçen veya 12-24 saat geçmesine rağmen, hâlen devam eden göğüs ağrısı ve iskemik semptomu bulunan hastalar

3. Acil koroner anjiografi yapılarak primer perkütan koroner girişim uygulanmış olan hastalar.

\section{Çalışmaya alınmama kriterleri}

1. Daha öncesine ait bypas öyküsü bulunan hastalar

2. Kardiyojenik şok tablosunda olan hastalar

3. STEMi tanısıyla trombolitik tedavi uygulanıp, ilk 24 saat içinde kurtarıcı PKG uygulanan hastalar.

4. LMCA $\geq \% 50$ darlığı olan hastalar

\section{Hasta verilerinin değerlendirilmesi}

Hastalara ait dosya kayıtlarına, hastane veri tabanı ve arşiv verileri kullanılarak ulaşıldı.

Yaş, cinsiyet, diyabetes mellitus, hipertansiyon, hi- 
perkolesterolemi, sigara içiciliği, geçirilmiş myokard enfarktüsü ve PKG öyküsü gibi klinik risk faktörleri değerlendirildi. Hastane dışı kardiyak arrest öyküsü, killip sınıflaması ile geliş nabız sayısı, sistolik kan basıncı (SKB), diastolik kan basıncı (DKB), boy, kilo, kreatinin klirensi $(\mathrm{CrCL})$ değerleri veri formuna işlendi. Vücut kitle indeksi (VKi) , hastaların kilolarının, boylarının metre cinsinden karesine bölünmeleriyle, $\mathrm{CrCL}$ ise cockgraft gault formülüyle hesaplandı.

Hastaların, başvuru sırasındaki üre, kreatinin $(\mathrm{Cr})$, kan şekeri, hemogram parametreleri, troponin I değerleri, başvuru anından sonra 24 saat içinde 12 saatlik açlığı takiben venöz kan örneklerinde LDL, HDL, ve TG düzeyleri ile yatışı sırasında bakılan en yüksek CK-MB değerleri veri formuna işlendi.

Hastaların EKG verileri Nihon Kohden Cardiofax GEM ECG-9020K (Tokyo, Japan) cihazı ile değerlendirildi. Incelenen EKG'lerde Mi yerleşim bölgeleri ST yükselmesi bulunan derivasyonlara göre anterior, anteroseptal, inferior ve lateral Mi olarak sınıflandırıldı.

Ekokardiyografik incelemeler, Vivid 3 (GE Medical Systems Ultrasound- United Kingdom) ekokardiyografi cihazı ile sol lateral dekubit pozisyonda parasternal uzun ve kısa aks, apikal 2,4,5 boşluk kesitlerinde yapıldı.

Hastalara yapılan koroner anjiografi ve perkutan koroner girişimler Toshiba Infinix-i INFX-8000H (Japanese) model anjiyografi cihazı ile yapıldı.

\section{Tanımlamalar}

Ağrının başlangıcından reperfüzyonun başarılmasına kadar geçen süre reperfüzyon zamanı, hastanın başvurusundan kateter laboratuvarında balon şişirilmesine kadar geçen süre kapı-balon zamanı olarak belirlendi.

Çoklu damar hastalığı, 2 veya 3 major epikardiyal koroner arterde $\% 50$ 'den fazla darlık bulunması olarak tanımlandı.
Hipertansiyon, istirahat sistolik ve/veya diastolik kan basıncının en az 140/90 mmHg olması veya daha öncesinde klinisyen tarafından tanısı konulmuş hastalığın bulunması, DM ise antidiyabetik ilaç kullanımı veya açlık kan glukozu düzeyinin $>126 \mathrm{mg} / \mathrm{dl}$ bulunması olarak tanımlandı.

Akut stent trombozu, stent yerleştirilmesinden sonraki ilk 24 saat içinde kardiyak semptomların yine başlaması ile beraber EKG'de ST elevasyonun görülmesi, kardiyak biyobelirteçlerde yükselme saptanması ve kontrol anjiografik görüntülemede önceki yerleştirilmiş stentin $5 \mathrm{~mm}$ bitişiğinde akımı kısıtlayan trombüs imajı görülmesi olarak tanımlandı.

Kardiyak ölüm, açıklanamayan ani ölüm veya akut MI, kalp yetmezliği, aritmilere bağlı ölüm olarak tanımlandı.

Kardiyojenik şok, sol ventrikül disfonksiyonu, sağ ventrikül infarktı veya mekanik komplikasyonlara bağI olarak hipoperfüzyon kliniği ile birlikte, 30 dk.'dan uzun süredir inatçı ve dirençli olarak sistolik kan basıncının< $80 \mathrm{mmHg}$ seyretmesi olarak tanımlandı.

Reinfarkt, serum CK-MB enzim düzeylerinde normalin üst limitinin iki katından fazla yükselme ve ST segmentlerinde yine yükselme olması olarak tanımlandı.

Rekürren iskemi, işlem sonrası klinik takiplerinde hastanın göğüs ağrısı yakınmasının yinelemesi ve/ veya takip EKG'lerinin değerlendirilmesinde dinamik değişikliklerin gözlenmesi olarak tanımlandı.

Komplet revaskülarizasyon, major epikardiyal koroner arterlerdeki (tüm proksimal, mid ve distal segmentler, major son ön inen arter diagonal dalları, circumflex marjinal dalları) lezyonların ( $\geq \% 50$ darlık, $\geq 2,5 \mathrm{~mm}$ çap olması koşuluyla) tamamına, hastane yatışı süresince PKG ile başarılı girişim yapılması olarak tanımlandı.

İnkomplet revaskülarizasyon, sorumlu lezyonda TIMI 3 akım sağlanamaması veya \%20'dan fazla rezidü lezyon kalması ve bir veya daha fazla sayıdaki önemli 
lezyonlara herhangi bir girişim yapılmaması olarak tanımlandı.

\section{Anjiografik parametreler ve tanımları}

Koroner anjiyografi, Sakarya Üniversitesi Eğitim ve Araştırma Hastanesi Kardiyoloji Anabilim Dalı Anjiyografi laboratuvarında, standart Judkins teknigi kullanılarak femoral arter yolu ile yapıldı. Koroner anjiografi ve perkütan koroner girişim, deneyimli (>yılda 75 vaka) 3 girişimsel kardiyoloji uzmanı tarafından yapıldı. Koroner anjiyografi sırasında kontrast ajan olarak noniyonik düşük osmolariteli kontrast maddeler kullanıldı ve her çekim sırasında yaklasık 6 ila $8 \mathrm{~mL}$ manuel olarak kontrast ajan injeksiyonu yapıldı.

Her hastaya koroner anjiografi işlemi öncesi 300 mg çiğnenebilir asetil salisilik asit ile oral klopidogrel 600 mg yükleme dozu verildi. İnfarkt ilişkili arterler LAD (sol ön inen arter), CX (sirkumfleks arter), RCA (sağ koroner arter) olarak olarak sınıflandıııldı. Koroner anjiografiler değerlendirilirken ayrıca infarkttan sorumlu arterde kollateral damar olup olmadığı belirlendi. İnfarkt sorumlu arterdeki (IRA) tıkanıklık derecesi, TIMI (Thrombolysis in myocardial infarction) sınıflamasına göre değerlendirildi.

Koroner anatomi belirlendikten sonra hastalara heparin $100 \mathrm{U} / \mathrm{kg}$ verildi. Her prosedür için, akut dönemdeki işlem başarısı; TIMı derece 3 akımın sağlanması ve işlem sonrası infarkt sorumlu arterde $\% 20$ 'den az darlığın kalması olarak tanımlandı.

İnfarkt sorumlu arterdeki veya diğer epikardiyal koroner arterlerdeki işlem başarısını etkileyebilecek ciddi kalsifikasyon, kronik total oklüzyon, bifurkasyon/trifurkasyon, osteal lezyon, lezyon uzunluğu $>20 \mathrm{~mm}$, trombüslü lezyon, anevrizma, ektazi varlığı da değerlendirildi.

\section{Syntax skoru ve anjiografilerin değerlendirilmesi}

Çapı 1,5 mm veya daha büyük damarlarda lümen daralmasına \%50'den fazla oranda neden olan koroner arter lezyonu olan vakalar çalışmaya alındı. Her bir lezyonun puanı ayrı ayrı hesaplanmak sureti, ile toplam Syntax skoru oluşturuldu9. Her bir lezyonun morfolojik özellikleri dikkate alınarak saptanan bir katsayı ile, lezyon puanlarını ayrı ayrı hesaplayan bir yazılım vasıtasıyla Syntax skoru belirlendi (Syntax score calculator v2.02, www.syntaxscore.com).

Çalışmamızda, başlangıç bazal Syntax skoru (bSS), 3 deneyimli girişimsel kardiyolog tarafından, hastaların klinik sonlanımlarından ve tedavi uygulamalarından habersiz olarak her lezyonun ayrı ayrı toplanmasıyla hesaplandı. STEMI hastaları, SYNTAX çalışmasında dışlama kriterleri arasında bulunduğundan, güncel skor algoritmasında bu hastalar için kabul edilmiş Syntax skor hesaplama yöntemi bulunmamaktadır. Bu nedenle, başlangıç Syntax skoru hesaplanırken, infarkt sorumlu arter tam tıkalı ise 3 aydan kısa süredir tıkalı olarak skorlandı ve algoritmaya dâhil edildi ve bu da tam tıkalı olan lezyonlara ilave 5 puan eklenmesine neden oldu.

Rezidüel Syntax skoru (rSS) ise, PKG işleminin tamamlanması sonrası, inkomplet revaskülarizasyon tanımlamasına uygun olarak:

1) Sorumlu lezyonda TIMI 3 akım sağlanamayan veya \%20'den fazla rezidü lezyonu kalan,

2) Farklı nedenlerle (osteal, kalsifik, ektazik, bifurkasyon, kronik total oklüzyon, lezyon uzunluğu $>20$ $\mathrm{mm}$, trombüslü lezyon vb.) revaskülarizasyon uygulanamayan, koronerlerdeki toplam Syntax skorunun hesaplanmasıyla bulundu. Yalnızca sorumlu lezyona başarılı PKG uygulanan, diğer lezyonlara müdahale edilmeyen hastalarda total tıkalı lezyonda tam açıklık sağlandığından başlangıç Syntax skorunda ilave 5 puanlık eksilme oldu. Sorumlu lezyona primer PKG sonrası devam eden semptomları olanlara yatışı esnasında kademeli PKG işlemi uygulandıktan sonra rSS hesaplandı, yakınmaları olmayanlara konservatif yaklaşım benimsendi ve taburculuk sonrası non-invaziv tetkik sonuçlarına göre invaziv girişim uygulanmasına karar verildi.

\section{Sonlanım noktaları}

Hastane içi major sonlanım noktaları, kardiyak mor- 
talite, reinfarkt, rekürren iskemi, acil hedef damar revaskülarizasyonu, akut stent trombozu olarak tanımlandı.

Hastane içi minör sonlanım noktaları ise ciddi kalp yetmezliği, kardiyojenik şok, inme/geçici iskemik atak, aritmi gelişimi, kardiyopulmoner resüsitasyon, ventilatör kullanımı, geçici pacemaker yerleştirilmesi, inotrop tedavi kullanımı, akut böbrek yetmezliği, hemodiyaliz uygulaması, gastrointestinal sistem kanamaları, kan transfüzyonu gereksinimi olarak belirlendi.

\section{İstatistiksel analiz}

İstatistiksel analiz SPSS 20.0 bilgisayar programı kullanılarak yapıldı. Kategorik değişkenler sayı veya yüzde, devamlı değişkenler ise ortalamaıstandart sapma şeklinde belirtildi. Kategorik değişkenlerin karşılaştırılmasında ki-kare testi kullanıldı. Devamlı değişkenlerin karşılaştırılmasında öncelikle parametrelerin normal dağılıma uygunluğuna Kolmogorov- Smirnov testiyle bakıldı. İki grup arasında normal dağılıma uymayan verilerin karşılaştırılmasında Mann-Whitney $\mathrm{U}$ testi uygulandı. Normal dağılıma uyan verilerin karşılaştırılmasında bağımsız örneklem t testi kullanıldı. $P$ degerinin 0,05 altında olması istatistiksel olarak anlamlı kabul edildi.

\section{BULGULAR}

Çalısmamıza, STEMI tanısı konularak primer PKG uygulanan 105 hasta alındı. Çalışmaya alınma kriterlerine uygun olmayan hastalar çalısma dışı bırakıldı.

Tablo 1. Risk faktörlerinin cinsiyete göre dağılımı.

\begin{tabular}{|c|c|c|c|c|c|}
\hline & & $\begin{array}{l}\text { Toplam } \\
(n=105)\end{array}$ & $\begin{array}{l}r S S=0 \\
(n=35)\end{array}$ & $\begin{array}{l}r S S \geq 1 \\
(n=70)\end{array}$ & $\mathbf{p}$ \\
\hline Yaş (yıl) & & $59,23 \pm 12,18$ & $53,77 \pm 11,6$ & $61,96 \pm 11,61$ & $0,001 *$ \\
\hline \multicolumn{6}{|l|}{ Cinsiyet ( $\mathrm{n} / \%$ ) } \\
\hline & Erkek & $86(81,9)$ & $32(37,2)$ & $54(62,8)$ & 0,128 \\
\hline & Kadın & $19(18,1)$ & $3(15,8)$ & $16(84,2)$ & \\
\hline Boy $(\mathrm{cm})$ & & $170,31 \pm 6,6$ & $173,2 \pm 5,59$ & $168,87 \pm 6,63$ & $0,001 *$ \\
\hline Vücut ağırlığı (kg) & & $79,49 \pm 10,51$ & $80,34 \pm 10,1$ & $79,06 \pm 10,75$ & 0,557 \\
\hline BKi $\left(\mathrm{kg} / \mathrm{m}^{2}\right)$ & & $27,37 \pm 2,98$ & $26,75 \pm 2,78$ & $27,69 \pm 3,05$ & 0,130 \\
\hline Kalp hızı (atım/dk.) & & $77,5 \pm 14,43$ & $76,69 \pm 14,45$ & $77,91 \pm 14,5$ & 0,683 \\
\hline Sistolik KB (mmHg) & & $121,21 \pm 24,22$ & $119,57 \pm 23,55$ & $122,03 \pm 24,68$ & 0,626 \\
\hline Diastolik KB (mmHg) & & $76,11 \pm 15,65$ & $75,63 \pm 14,47$ & $76,36 \pm 16,31$ & 0,823 \\
\hline Killip sınıfi (n / \%) & & $16(15,2)$ & $2(5,7)$ & $14(20)$ & 0,103 \\
\hline Ejeksiyon fraksiyonu (\%) & & $43,38 \pm 7,25$ & $43,57 \pm 6,91$ & $43,29 \pm 7,46$ & 0,850 \\
\hline Hipertansiyon (n / \%) & & $52(49,5)$ & $10(28,5)$ & $42(60)$ & $0,005^{*}$ \\
\hline Diyabetes Mellitus (n / \%) & & $25(23,8)$ & $5(14,2)$ & $20(28,5)$ & 0,168 \\
\hline Hiperlipidemi (n / \%) & & $17(16,2)$ & $6(17,1)$ & $11(15,7)$ & 0,851 \\
\hline Sigara (n / \%) & & $59(56,2)$ & $26(74,2)$ & $33(47,1)$ & $0,015^{*}$ \\
\hline Geçirilmiş MI (n / \%) & & $5(4,8)$ & $2(5,7)$ & $3(4,2)$ & 0,542 \\
\hline Geçirilmiş PKG (n / \%) & & $6(5,7)$ & $2(5,7)$ & $4(5,7)$ & 0,655 \\
\hline \multicolumn{6}{|l|}{ MI lokalizasyonu (n / \%) } \\
\hline & Anterior MI & $39(37,1)$ & $16(45,7)$ & $23(32,8)$ & \\
\hline & Anteroseptal MI & $16(15,2)$ & $5(14,2)$ & $11(15,7)$ & 0,277 \\
\hline & İnferior MI & $47(44,8)$ & $12(34,2)$ & $35(50)$ & \\
\hline & Lateral MI & $3(2,9)$ & $2(5,7)$ & $1(1,4)$ & \\
\hline Kreatinin (mg/dl) & & $0,98 \pm 0,27$ & $0,98 \pm 0,21$ & $0,98 \pm 0,3$ & 0,553 \\
\hline LDL- Kolesterol (mg/dl) & & $122,35 \pm 44,76$ & $123,8 \pm 41,04$ & $121,63 \pm 46,78$ & 0,816 \\
\hline Trigliserit (mg/dl) & & $156,44 \pm 130,09$ & $170,49 \pm 177,65$ & $149,41 \pm 99,02$ & 0,726 \\
\hline HDL- Kolesterol (mg/dl) & & $42,45 \pm 29,54$ & $37,86 \pm 8,52$ & $44,74 \pm 35,54$ & 0,208 \\
\hline Kreatinin Klirensi (ml/dk./1.73 $\left.\mathrm{m}^{2}\right)$ & & $94,33 \pm 28,26$ & $100,13 \pm 27,64$ & $91,43 \pm 28,31$ & 0,137 \\
\hline Zirve CK-MB (U/I) & & $237,46 \pm 217,67$ & $213,74 \pm 174,53$ & $249,31 \pm 236,59$ & 0,878 \\
\hline Geliş Troponin I (ng/ml) & & $5,12 \pm 11,26$ & $4,62 \pm 7,46$ & $5,38 \pm 12,78$ & 0,685 \\
\hline Hemoglobin (g/dl) & & $13,91 \pm 1,61$ & $14,19 \pm 1,22$ & $13,77 \pm 1,76$ & 0,211 \\
\hline Hematokrit & & $41,48 \pm 4,75$ & $42,01 \pm 3,44$ & $41,22 \pm 5,29$ & 0,3 \\
\hline
\end{tabular}

Veriler ortalama Łstandart sapma biçiminde gösterilmiştir. 
Komplet revaskülarizasyon yapılan ve rSS=0 olan grup ile inkomplet revaskülarizasyon yapılan ve $r S S \geq 1$ olan grupların karşılaştırmaları yapıldı.

\section{Klinik, demografik özellikler ve laboratuvar bulguları}

Vakaların $35^{\prime}$ inde $(\% 33,3)$ rSS=0, 70'inde $(\% 67,7)$ rSS $\geq 1$ bulundu. Vakaların 86'sı (\%81,9) erkek, 19'u $(\% 18,1)$ kadındı (Tablo 1). Tüm vakaların yaş ortalaması $59,23 \pm 12,18$ yıldı. Çalışmaya alınan hastaların demografik, klinik ve laboratuvar özellikleri Tablo 1'de verilmiştir.

\section{Anjiografik ve prosedürel karakteristikler}

Hastaların prosedür öncesi anjiografik verilerine bakıldığında infarkt sorumlu arterin $58(\% 55,2)$ vakada LAD, $10(\% 9,5)$ vakada CX, $37(35,2)$ vakada RCA olduğu görülmektedir ve gruplar arasında istatistiksel anlamlı fark yoktur ( $p>0,05)$. Yaygınlığa bakıldığında tek damar hastalığının $45(\% 42,9)$ hastada, iki damar hastalığının $39(\% 37,1)$ hastada, üç damar hastalığının ise 21 (\%20) hastada olduğu görülmektedir ve gruplar arasında anlamlı fark bulunmaktadır $(p<0,05)$.

Tablo 2. Çalışmaya alınan hastaların anjiografik ve prosedürel karakteristikleri.

\begin{tabular}{|c|c|c|c|c|c|}
\hline & & $\begin{array}{l}\text { Toplam } \\
(n=105)\end{array}$ & $\begin{array}{l}r S S=0 \\
(n=35)\end{array}$ & $\begin{array}{l}r S S \geq 1 \\
(n=70)\end{array}$ & p \\
\hline \multicolumn{6}{|l|}{ Sorumlu lezyon } \\
\hline & LAD & $58(55,2)$ & $22(62,8)$ & $36(51,4)$ & \\
\hline & $\mathrm{CX}$ & $10(9,5)$ & $4(11,4)$ & $6(8,5)$ & 0,349 \\
\hline & RCA & $37(35,2)$ & $9(25,7)$ & $28(40)$ & \\
\hline \multicolumn{6}{|l|}{ Yaygınlık } \\
\hline & Tek damar & $45(42,9)$ & $34(97,1)$ & $11(15,7)$ & \\
\hline & İki damar & $39(37,1)$ & $1(2,8)$ & $38(54,2)$ & $0,000 *$ \\
\hline & Üç damar & $21(20,0)$ & 0 & $21(30)$ & \\
\hline Toplam lezyon sayısı & & $2,27 \pm 1,44$ & $1,06 \pm 0,24$ & $2,87 \pm 1,41$ & 0,000 \\
\hline Stent kullanımı & & $101(96,2)$ & $35(100)$ & $66(94,2)$ & 0,299 \\
\hline Stent uzunluğu (mm) & & $22,66 \pm 5,86$ & $20,83 \pm 5,24$ & $23,64 \pm 5,98$ & $0,021 *$ \\
\hline Stent çapı (mm) & & $2,99 \pm 0,41$ & $3,13 \pm 0,4$ & $2,91 \pm 0,4$ & $0,003^{*}$ \\
\hline Toplam stent sayısı & & $1,27 \pm 0,57$ & $1,18 \pm 0,46$ & $1,32 \pm 0,61$ & 0,213 \\
\hline \multicolumn{6}{|l|}{ Stent tipi } \\
\hline & Çıplak metal & $83(79)$ & $31(88,5)$ & $52(74,2)$ & 0,150 \\
\hline & İlaç kaplı & $18(17,1)$ & $4(11,4)$ & $14(20)$ & 0,410 \\
\hline \multicolumn{6}{|l|}{ TIMı başlangıç (infarkt arteri) } \\
\hline & $0 / 1$ & $79(75,2)$ & $24(68,5)$ & $55(78,5)$ & \\
\hline & 2 & $4(3,8)$ & $2(5,7)$ & $2(2,8)$ & 0,526 \\
\hline & 3 & $22(21)$ & $9(25,7)$ & $13(18,5)$ & \\
\hline \multicolumn{6}{|l|}{ TIMI son (infarkt arteri) } \\
\hline & $0 / 1$ & $6(5,8)$ & 0 & $6(8,5)$ & \\
\hline & 2 & $7(6,7)$ & $2(5,7)$ & $5(7,1)$ & 0,342 \\
\hline & 3 & $92(87,6)$ & $33(94,2)$ & $59(84,2)$ & \\
\hline Tirofiban kullanımı & & $35(33,3)$ & $10(28,5)$ & $25(35,7)$ & 0,608 \\
\hline Predilatasyon & & $63(60)$ & $22(62,8)$ & $41(58,5)$ & 0,833 \\
\hline Postdilatasyon & & $6(5,7)$ & $1(2,8)$ & $5(7,1)$ & 0,661 \\
\hline Trombüs aspirasyonu & & $7(6,7)$ & $3(8,5)$ & $4(5,7)$ & 0,684 \\
\hline Bazal Syntax Skoru (bSS) & & $14,72 \pm 6,92$ & $11,47 \pm 6,24$ & $16,34 \pm 6,7$ & $0,001^{*}$ \\
\hline Rezidüel Syntax Skoru (rSS) & & $4,16 \pm 5,35$ & 0 & $6,24 \pm 5,47$ & $0,000 *$ \\
\hline Reperfüzyon zamanı (dk.) & & $331,29 \pm 225,17$ & $326,14 \pm 231,1$ & $333,86 \pm 223.8$ & 0,869 \\
\hline Kapı balon zamanı (dk.) & & $50,43 \pm 16,54$ & $49 \pm 17,14$ & $51,14 \pm 16,31$ & 0,534 \\
\hline Lezyon uzunluğu >20 mm & & $35(33,3)$ & $10(28,5)$ & $25(35,7)$ & 0,608 \\
\hline Kronik total oklüzyon & & $27(25,7)$ & $7(20,0)$ & $20(28,6)$ & 0,477 \\
\hline Bifurkasyon lezyonu & & $11(10,5)$ & $1(2,9)$ & $10(14,3)$ & 0,095 \\
\hline Osteal lezyon & & $5(4,8)$ & $1(2,9)$ & $4(5,7)$ & 0,663 \\
\hline Trombüslü lezyon & & $4(3,8)$ & 0 & $4(5,7)$ & 0,299 \\
\hline Ektazik lezyon & & $17(16,2)$ & $8(22,9)$ & $9(12,9)$ & 0,303 \\
\hline Kalsifik lezyon & & $1(0,9)$ & 0 & $1(1,4)$ & 0,667 \\
\hline
\end{tabular}

Veriler ortalama £standart sapma ve $n(\%)$ biçiminde gösterilmiştir. 
Hastaların prosedür öncesi anjiografik görüntülerinden Syntax skorlama sistemi ile hesaplanan bSS ortalaması 14,72 $\pm 6,92$, PKG sonrası hesaplanan rSS ortalaması 4,16 $\pm 5,35$ olarak bulunmuştur. KR yapılan $r S S=0$ olan grubun bSS ortalaması $11,47 \pm 6,24$, IR yapılan rSS $\geq 1$ olan grubun ise $16,34 \pm 6,7$ hesaplanmış olup, gruplar arasında istatistiksel anlamlı fark bulunmaktadır $(p<0,05)$.

Çalışmaya alınan hastaların anjiografik ve prosedürel karakteristikleri Tablo 2'de verilmiştir.

\section{Hastane içi sonlanım noktaları}

Major sonlanım noktaları açısından rekürren iskemi hariç gruplar arasında istatistiksel anlamlı fark bulunmamaktadır $(p>0,05)$. Mekanik komplikasyonlara bakıldığında, toplamda $2(\% 1,9)$ hastada görülmüştür. İlk hastada prosedür sonrası klinik takiplerinde hemodinamik bozulmaya yol açmayan ekokardiyografi ile tespit edilmiş ventriküler septal defekt gözlenmiş, elektif şartlarda cerrahiye yönlendirilmiş, ikinci hastada ise yatışının ikinci gününde hemodinamik bozukluk nedeniyle yapılan ekokardiyografide inferior duvarda lokalize serbest duvar rüptürü gözlenmiş, acil şartlarda defekt kateter laboratuvarında amplatzer marka tıkayıcı cihaz ile kapatılarak elektif şartlarda cerrahiye yönlendirilmiştir. Minör sonlanım

Tablo 3. Çalışmaya alınan hastaların hastane içi sonlanım noktaları.

\begin{tabular}{|c|c|c|c|c|}
\hline & $\begin{array}{l}\text { Toplam } \\
(n=105)\end{array}$ & $\begin{array}{l}r S S=0 \\
(n=35)\end{array}$ & $\begin{array}{l}r S S \geq 1 \\
(n=70)\end{array}$ & $\mathbf{p}$ \\
\hline Kardiyovasküler ölüm & $5(4,8)$ & $1(2,8)$ & $4(5,7)$ & 0,663 \\
\hline Reinfarkt & $5(4,8)$ & $1(2,8)$ & $4(5,7)$ & 0,663 \\
\hline Kalp yetmezliği & $13(12,4)$ & $2(5,7)$ & $11(15,7)$ & 0,211 \\
\hline Aritmi & $12(11,4)$ & $2(5,7)$ & $10(14,2)$ & 0,363 \\
\hline İnme/TiA & $4(3,8)$ & $1(2,8)$ & $3(4,2)$ & 0,593 \\
\hline Acil damar revaskülarizasyonu & $4(3,8)$ & $1(2,8)$ & $3(4,2)$ & 0,593 \\
\hline Rekürren iskemi & $21(20)$ & $2(5,7)$ & $19(27,1)$ & $0,020 *$ \\
\hline Akut stent trombozu & $3(2,9)$ & $1(2,8)$ & $2(2,8)$ & 0,708 \\
\hline Mekanik komplikasyon & $2(1,9)$ & 0 & $2(2,8)$ & 0,601 \\
\hline Gastrointestinal kanama & $3(2,9)$ & 0 & $3(4,2)$ & 0,549 \\
\hline Geçici pacemaker & $4(3,8)$ & 0 & $4(5,7)$ & 0,299 \\
\hline İnotrop tedavi & $8(7,6)$ & $1(2,8)$ & $7(10)$ & 0,264 \\
\hline Mekanik ventilatör & $5(4,8)$ & $1(2,8)$ & $4(5,7)$ & 0,663 \\
\hline Kan transfüzyonu & $3(2,9)$ & 0 & $3(4,2)$ & 0,549 \\
\hline Akut böbrek yetmezliği/Diyaliz & $3(2,9)$ & 0 & $3(4,2)$ & 0,549 \\
\hline
\end{tabular}

Veriler n (\%) biçiminde gösterilmiştir. noktalarına bakıldığında, gruplar arasında anlamlı istatistiksel fark saptanmamıştır $(p>0,05)$. Tablo 3'te hastane içi sonlanım noktaları gösterilmiştir.

\section{TARTIŞMA}

Çalışmamızın ana bulguları, inkomplet revaskülarizasyonun dolaylı bir belirteci olarak residüel Syntax skoru (rSS) hastane içi sonlanımların öngördürülmesinde yeterli olamamaktadır. Syntax skoru, revaskülarizasyon kararlarının doğru olarak verilmesini kolaylaştıran, uzun ve kısa dönem takipte mortalite ve morbiditeyi öngördürebilen bir anjiografik skorlama sistemidir. SYNTAX çalışmasında, STEMI hastaları dışlandığından, bu gruptaki hastalarda skoru hesaplama yöntemi bulunmamaktadır. Fakat, Garg ve ark.'nın ${ }^{12}$ yaptığı 807 STEMı hastasının alındığı bir çalışmada, Syntax skoru STEMI hastalarına uyarlanarak düşük, orta ve yüksek olarak gruplara ayrılmış, Syntax skoru> 16 olan yüksek riskli grupta 1 yıllık takipte mortalite, reinfarkt, major advers kardiyak olaylar ve stent trombozunun anlamlı derecede yüksek olduğu gösterilmiştir. Rezidüel Syntax skoru tanımının ilk olarak yapıldığı, Genereux ve ark.'nın ${ }^{13}$ gerçekleştirmiş olduğu bir çalışmaya erken invaziv strateji ile yönetilen orta yüksek riskli AKS tanısı alan 2686 hasta alınmış, PKG sonrası rezidüel koroner darlıkların karmaşıklığını ve yaygınlığını belirlemek için inkomplet revaskülarizasyonun bir belirteci olarak rSS hesaplanmıştır. Sınıflara ayrılan rSS ile 30 günlük ve 1 yıllık tüm nedenlerle ölüm, kardiyak ölüm, MI, planlanmamış yineleyen revaskülarizasyonların ilişkisi incelenmiş, tüm risk gruplarında sonlanım noktaları komplet revaskülarizasyon yapılan gruba göre anlamlı yüksek bulunmuştur. Çalışmamızın bu çalışmadan farkı hastalarımızın tamamının STEMı tanılı olmasıdır. Çalışmamıza en fazla benzerlik gösteren Magro ve ark.'nın ${ }^{11} 736$ STEMI hastası üzerinde yaptığı bir çalışmada, prosedür öncesi Syntax skorları ve sonrasında tel ile sorumlu lezyon geçildikten sonraki Syntax skorları hesaplanmış, prosedür öncesi Syntax skorları ile daha fazla ilişkili olmak üzere yüksek Syntax skoru bulunan grupta major advers kardiyak olaylar açısından primer sonlanım noktaları anlamlı olarak yüksek bulunmuştur. Aggarwal ve ark. ${ }^{14}$ tarafından yapılan bir metaanaliz- 
de, 9 ayrı IR ve KR'yi karşılaştıran çalışma incelenmiş, toplamda 37116 hastanın ortalama 29 aylık takibinde KR grubunda IR grubuna göre mortalite, nonfatal MI, sonraki CABG prosedürleri gereksinimleri anlamIı düşük bulunmakla birlikte, yineleyen PKG'ler açısından anlamlı fark gözlenmemiştir.

Literatürde, IR ile KR karşılaştırma çalışmalarının büyük çoğunluğunda AHA kılavuzunda hemodinamik anormallik yokluğunda yalnızca sorumlu damara müdahale önerildiği için akut MI hastaları çalışma dışında bırakılmıştır. Akut $\mathrm{Ml}$ hastalarının yaklaşık \%30-\%60'ında çoklu damar hastalığı tespit edilmesine rağmen, PKG genellikle infarkt sorumlu lezyona uygulanır. Hyun su Jo ve ark.'nın ${ }^{15} 1094$ STEMI hastası üzerinde yapmış olduğu sorumlu lezyona revaskülarizasyon ile tüm lezyonlara komplet revaskülarizasyonun karşılaştırıldığı bir çalışmada, hastane içi mortalite sorumlu lezyon revaskülarizasyonu grubunda anlamlı olarak yüksek bulunmuştur. Çalışmamızda, kılavuz önerilerine uygun olarak prosedür sırasında yalnızca sorumlu lezyona PKG uygulandı. Kronik total oklüzyonları olan veya çeşitli nedenlerle (tortuozite, kalsifikasyon, anevrizma, osteal, LMCA, bifurkasyon) rezidü lezyonlara invaziv girişimin riskli olabileceği hastalarımızın bir kısmı klinik endikasyonlar dâhilinde bypas cerrahisine yönlendirildi. Revaskülarizasyona uygun rezidü lezyonları kalan hastalara da primer girişim sonrası semptomları devam etmesi koşuluyla yatışı sırasında kademeli PKG uygulandı. Sonuç olarak, rekürren iskemi dışında hiçbir hastane içi sonlanım noktasında anlamlı fark bulamadık. Çalışmamıza kardiyojenik şokla gelen, bypas öyküsü olan, LMCA'da kritik lezyonu olan nispeten yüksek riskli sayılabilecek hastaları almadık. Basal Syntax skoru ortalamamız düşüktü. Bu nedenle hastane içi major önemli kardiyak olayların sık olmadığını düşünüyoruz. Ek olarak, hastalarımızda başlangıçtaki anjiografilerinde sorumlu lezyonda TIMI 3 akım 22 hastada (\%21) mevcuttu. Kateter laboratuvarına transfer sürecine kadar acildeki ilk başvurusunda hastaların hepsine tanıları konar konmaz klopidogrel yükleme dozlarını, aspirin ve heparin tedavilerini uyguladık. Bazı hastaların geç dönemde başvurusu nedeniyle spontan reperfüzyon oranımız yüksekti. Bu nedenle erken etkin tedavimi- zin katkısıyla sonlanım noktalarımız açısından gruplar arasında anlamlı fark bulunmadığını düşünüyoruz. Stabil düşük riskli koroner arter hastalarında İR'ye rağmen, optimal medikal tedavi ile semptomlarda azalma sağlanabileceği COURAGE (Clinical Outcomes Utilizing Revascularization and Aggressive Drug Evaluation) çalışmasında ${ }^{16}$ gösterilmiştir. Bu çalışma, stabil anjinası olan hastalarda optimal medikal tedavi ile kıyaslandığında rutin revaskülarizasyonun yararını göstermede yetersiz kalmıştır. COURAGE çalışmasında, başlangıç fonksiyonel testlerde orta-ciddi düzeyde iskemisi ve randomizasyondan 18 ay sonra anlamlı rezidüel iskemisi (>\% 5 iskemik miyokard) olan hastalarda sonraki ölüm ve MI oranlarında artış olabileceği gösterilmiştir. Bu bağlamda, akut MI seyrinde sorumlu lezyon açıldıktan sonra rutin yaklaşım olarak değil de kılavuz önerilerine uygun olarak stres testlerinden sonra kademeli PKG yapmak mantıklı olacaktır. FAME (Fractional Flow Reserve Versus Angiography for Multivessel Evaluation) çalışmasının ışığında ${ }^{17}$, sorumlu lezyon açıldıktan sonra rezidüel lezyonlar her ne kadar \%50-\%70 darlığa yol açsa da klinik olarak iskemiye yol açmayabilir.

\section{Çalışmanın kısıtıııkları}

Çalışmamızın kısıtlılıklarını irdeleyecek olursak, her ne kadar anjiografik ve prosedürel verilerimiz en son detaylı olarak incelense de çalışmamız doğasında hastaların dosyaları taranarak yapıldığı için retrospektif tasarımlı bir çalışmaydı. TIMI akım dereceleri dışında reperfüzyon belirteci olarak kullanılabilecek miyokard perfüzyon derecesi (myocardial blush grade) ve ST segment rezolusyonu gibi parametreleri incelemedik. Çalışmamızda, hasta sayısının ve buna bağlı olarak sonlanım noktalarının az olmasının sonuçların istatistiki anlama ulaşmasını engellemiş olabileceğini düşünüyoruz. Ayrıca, dışlama kriterlerine göre çalışma dışında bıraktığımız hastaların başlangıç Syntax skor ortalamamızın düşük çıkmasına neden olarak, sonlanım noktalarında istatistiki anlamlı fark çıkmamasında bir etken olabildiğini düşünmekteyiz. 


\section{SONUÇ}

STEMI hastalarında, hastane içi sonlanım noktalarını öngördürücü olarak inkomplet revaskülarizasyonun dolaylı bir belirteci olan rezidüel Syntax skoru yeterli olamamaktadır. Hastaların klinik, anjiografik, laboratuvar verilerini kombine olarak değerlendirebilecek farklı risk skorlama yöntemlerinin geliştirilmesi yararIı olacaktır. Bu konuda yapılacak uzun ve kısa dönem mortaliteyi göstermek açısından daha geniş kapsamlı randomize kontrollü çalışmalara gereksinim vardır. Ayrıca gelecekteki çalışmalar tasarlanırken, revaskülarizasyon tedavilerinin yarar ve zararları lezyonların anjiografik özelliklerine ilave olarak fonksiyonel ve fizyolojik özellikleri değerlendirildikten sonra iskemi kılavuzluğunda revaskülarizasyon stretejilerinin benimsenmesi yararlı olacaktır.

\section{KAYNAKLAR}

1. Onat $A$, Uğur $M$, Tuncer $M$ et al. Age at death in the Turkish Adult Risk Factor Study: temporal trend and regional distribution at 56,700 person-years' follow-up. Türk Kardiyol Dern Arş 2009;37(3):155 60.

2. Onat $A$, Uğur $M$, Çiçek $G$ et al. The Turkish Adult Risk Factor survey 2009: similar cardiovascular mortality in rural and urban areas. Türk Kardiyol Dern Arş 2010;38:159-63.

3. Keeley EC, Boura JA, Grines CL. Primary angioplasty versus intravenous thrombolytic therapy for acute myocardial infarction: a quantitative review of 23 randomised trials. Lancet 2003;361:13-20. http://dx.doi.org/10.1016/S0140-6736(03)12113-7

4. Hannan EL, Racz M, Holmes DR, et al. Impact of completeness of percutaneous coronary intervention revascularization on long-term outcomes in the stent era. Circulation 2006;113:2406-12.

http://dx.doi.org/10.1161/CIRCULATIONAHA.106.612267

5. Hannan EL, Wu C, Walford G, et al. Incomplete revascularization in the era of drug-eluting stents: impact on adverse outcomes. JACC Cardiovasc Interv 2009;2:17-25. http://dx.doi.org/10.1016/j.jcin.2008.08.021

6. Kim YH, Park DW, Lee JY, et al. Impact of angiographic complete revascularization after drug-eluting stent implantation or coronary artery bypass graft surgery for multivessel coronary artery disease. Circulation 2011;123:2373-81. http://dx.doi.org/10.1161/CIRCULATIONAHA.110.005041

7. van den Brand MJ, Rensing BJ, Morel MA, et al. The effect of completeness of revascularization on event-free survival at one year in the ARTS trial. J Am Coll Cardiol 2002;39:559-64. http://dx.doi.org/10.1016/S0735-1097(01)01785-5

8. Sianos G, Morel MA, Kappetein AP, et al. The SYNTAX Score: an angiographic tool grading the complexity of coronary artery disease. Euro Intervention 2005;1:219-227.
9. Palmerini T, Genereux P, Caixeta A, et al. Prognostic value of the SYNTAX score in patients with acute coronary syndromes undergoing percutaneous coronary intervention: analysis from the ACUITY (Acute Catheterization and Urgent Intervention Triage StrategY) trial. J Am Coll Cardiol 2011;57:2389 -97. http://dx.doi.org/10.1016/j.jacc.2011.02.032

10. Girasis C, Garg S, Raber L, et al. SYNTAX score and clinical SYNTAX score as predictors of very long-term clinical outcomes in patients undergoing percutaneous coronary interventions: a substudy of SIRolimus-eluting stent compared with pacliTAXel-eluting stent for coronary revascularization (SIRTAX) trial. Eur Heart J 2011;32:3115-27. http://dx.doi.org/10.1093/eurheartj/ehr369

11. Magro M, Nauta S, Simsek C et al. Value of the SYNTAX score in patients treated by primary percutaneous coronary intervention for acute ST-elevation myocardial infarction: The MI SYNTAXscore study. Am Heart J 2011;161:771-81. http://dx.doi.org/10.1016/j.ahj.2011.01.004

12. Garg S, Sarno G, Serruys PW et al. Prediction of 1-year clinical outcomes using the SYNTAX score in patients with acute STsegment elevation myocardial infarction undergoing primary percutaneous coronary intervention: a substudy of the STRATEGY (Single High-Dose Bolus Tirofiban and Sirolimus-Eluting Stent Versus Abciximab and Bare-Metal Stent in Acute Myocardial Infarction) and MULTISTRATEGY (Multicenter Evaluation of Single High-Dose Bolus Tirofiban Versus Abciximab With Sirolimus-Eluting Stent or Bare-Metal Stent in Acute Myocardial Infarction Study) trials. JACC Cardiovasc Interv 2011;4:66-75.

http://dx.doi.org/10.1016/j.jcin.2010.09.017

13. Genereux P, Palmerini T, Caixeta A, et al. Quantification and impact of untreated coronary artery disease after percutaneous coronary intervention: the residual SYNTAX (Synergy Between $\mathrm{PCl}$ with Taxus and Cardiac Surgery) score. J Am Coll Cardiol 2012;59:2165-74.

http://dx.doi.org/10.1016/j.jacc.2012.03.010

14. Aggarwal V, Rajpathak S, Singh M, et al. Clinical outcomes based on completeness of revascularisation in patients undergoing percutaneous coronary intervention: a meta-analysis of multivessel coronary artery disease studies. Eurointervention 2012;7:1095-102. http://dx.doi.org/10.4244/EIJV7I9A174

15. Jo HS, Park JS, Sohn JW, et al. Culprit-lesion only versus multivessel revascularization using drug-eluting stents in patients with ST-segment elevation myocardial infarction: A Korean acute myocardial infarction registry-based analysis. Korean Circ J 2011;41:718-725. http://dx.doi.org/10.4070/kcj.2011.41.12.718

16. Shaw LJ, Berman DS, Maron DJ et al. Optimal medical therapy with or without percutaneous coronary intervention to reduce ischemic burden: results from the Clinical Outcomes Utilizing Revascularization and Aggressive Drug Evaluation (COURAGE) trial nuclear substudy. Circulation 2008;117:1283-91. http://dx.doi.org/10.1161/CIRCULATIONAHA.107.743963

17. Tonino PA, De Bruyne B, Pijls NH et al. Fractional flow reserve versus angiography for guiding percutaneous coronary intervention. N Engl J Med 2009;360:213-24. http://dx.doi.org/10.1056/NEJMoa0807611 